\title{
A Dicarboxylate Transporter, LjALMT4, Mainly Expressed in Nodules of Lotus japonicus
}

\author{
Kojiro Takanashi,, ${ }^{1,2}$ Takayuki Sasaki, ${ }^{3}$ Tomohiro Kan, ${ }^{1}$ Yuka Saida, ${ }^{1}$ Akifumi Sugiyama, ${ }^{1}$ \\ Yoko Yamamoto, ${ }^{3}$ and Kazufumi Yazaki ${ }^{1}$ \\ ${ }^{1}$ Research Institute for Sustainable Humanosphere, Kyoto University, Uji 611-0011, Japan; ${ }^{2}$ Institute of Mountain Science, \\ Shinshu University, Matsumoto 390-8621, Japan; and ${ }^{3}$ Institute of Plant Science and Resources, Okayama University, \\ Kurashiki 710-0046, Japan
}

Accepted 12 May 2016.

Legume plants can establish symbiosis with soil bacteria called rhizobia to obtain nitrogen as a nutrient directly from atmospheric $\mathrm{N}_{2}$ via symbiotic nitrogen fixation. Legumes and rhizobia form nodules, symbiotic organs in which fixed-nitrogen and photosynthetic products are exchanged between rhizobia and plant cells. The photosynthetic products supplied to rhizobia are thought to be dicarboxylates but little is known about the movement of dicarboxylates in the nodules. In terms of dicarboxylate transporters, an aluminum-activated malate transporter (ALMT) family is a strong candidate responsible for the membrane transport of carboxylates in nodules. Among the seven ALMT genes in the Lotus japonicus genome, only one, LjALMT4, shows a high expression in the nodules. LjALMT4 showed transport activity in a Xenopus oocyte system, with LjALMT4 mediating the efflux of dicarboxylates including malate, succinate, and fumarate, but not tricarboxylates such as citrate. LjALMT4 also mediated the influx of several inorganic anions. Organ-specific gene expression analysis showed LjALMT4 mRNA mainly in the parenchyma cells of nodule vascular bundles. These results suggest that LjALMT4 may not be involved in the direct supply of dicarboxylates to rhizobia in infected cells but is responsible for supplying malate as well as several anions necessary for symbiotic nitrogen fixation, via nodule vasculatures.

Symbiotic nitrogen fixation (SNF) is one of the biggest contributors to the nitrogen cycle on earth, responsible for the annual fixation of approximately 33 to 46 million tons of atmospheric $\mathrm{N}_{2}$ (Herridge et al. 2008). Most SNF is mediated by speciesspecific legume-rhizobia symbiosis. Invading rhizobia are accepted by plant cells via endocytosis, resulting in the formation of intracellular symbiosomes surrounded by a plantderived peribacteroid membrane; proteomic approaches have identified several transporters and enzymes in these symbiosomes (Clarke et al. 2015; Saalbach et al. 2002; Wienkoop and Saalbach 2003). In symbiosomes, rhizobia become mature bacteroids, resulting in the formation of specialized organs called nodules on the root, in which SNF occurs (Oldroyd et al. 2011; Udvardi and Poole 2013). While supplying fixed

Corresponding author: K. Yazaki; Telephone: +81-774-38-3617; Fax: +81774-38-3623; E-mail: yazaki@ rish.kyoto-u.ac.jp

*The $\boldsymbol{e}$-Xtra logo stands for "electronic extra" and indicates that six supplementary figures and two supplementary tables are published online.

() 2016 The American Phytopathological Society nitrogen to plants, bacteroids receive their carbon source from plants. Biochemical studies have shown that dicarboxylates such as malate and succinate are highly permeable across isolated peribacteroid membranes from soybeans (Price et al. 1987; Udvardi and Day 1997; Udvardi et al. 1988). Similarly, nitrogen fixation by isolated bacteroids from several legume plants was found to be highly stimulated by the addition of dicarboxylates but not by sucrose (Yurgel and Kahn 2004), indicating that dicarboxylates are the primary carbon source provided by host plants to bacteroids. Nodules of the nonlegume plant Alnus glutinosa were found to express a dicarboxylate transporter, AgDCAT1. This protein, a member of a nitrate transporter family (Léran et al. 2014), was shown to have uptake activity for dicarboxylates such as malate and succinate (Jeong et al. 2004), suggesting that AgDCAT1 may provide dicarboxylates to the bacteroid. To date, however, neither an influx nor an efflux transporter for dicarboxylates has been identified in the nodules of legume plants.

An aluminum-activated malate transporter (ALMT) was first detected in wheat (Triticum aestivum) and was shown to transport malate in response to exposure to aluminum (Delhaize et al. 2004; Sasaki et al. 2004). Arabidopsis AtALMT1 was also reported to be a malate efflux transporter involved in aluminum detoxification (Hoekenga et al. 2006). Because these ALMTs were found to transport malate, to be expressed in roots, and to be activated by exposure to aluminum, they were initially thought to function as aluminum detoxification proteins in plants. However, additional studies on more than 10 members of the ALMT family suggested that these transporter proteins have several physiological functions, such as stomatal movement and ion homeostasis, that are localized either at the plasma membrane or tonoplast (De Angeli et al. 2013b; Gruber et al. 2010; Piñeros et al. 2008). Some ALMTs can mediate the efflux of fumarate as well as malate (Kovermann et al. 2007; Meyer et al. 2011), suggesting that the ALMT family may be candidate transporters of dicarboxylates, mediating its movement across one or both the peribacteroid or plasma membranes of legume plant nodules.

This study has assessed the association between ALMT proteins in Lotus japonicus and SNF. Of the seven ALMT proteins expressed in this plant, one, LjALMT4, is highly expressed in nodules. When expressed in Xenopus laevis oocytes, this protein was found to mediate the efflux of dicarboxylates, including fumarate and succinate. Moreover, LjALMT4 was found to be specifically expressed in nodule vascular bundles, suggesting that LjALMT4 is not a transporter at the peribacteroid membrane but is involved in transporting 
carbon sources as well as inorganic anions to and from Lotus nodule vasculatures.

\section{RESULTS}

ALMT genes in the L. japonicus genome.

To assess the function of ALMT proteins in L. japonicus, we first evaluated the number of ALMT genes in the L. japonicus genome database (ver. 2.5). Using ALMT sequences of Arabidopsis as queries, seven putative $A L M T$ genes were detected in Lotus chromosomes. To determine which of these ALMT members function in nodules, organ-specific expression analysis was performed. Total RNA was extracted from the organs of plants that had or had not been inoculated with the rhizobium species Mesorhizobium loti. Semiquantitative reverse transcriptionpolymerase chain reaction (RT-PCR) showed that the expressions of three ALMT genes (LjALMT3, LjALMT4, and LjALMT5) were detected in nodules, whereas four other $A L M T$ genes could not be detected in the underground parts of the plants (Fig. 1A). Then, the expression profiles of LjALMT3, LjALMT4, and LjALMT5 were analyzed in more detail, using quantitative RTPCR (Fig. 1B). LjALMT3 and LjALMT5 were expressed mostly in leaves and the expression of LjALMT4 was detected mainly in seeds and nodules. While the expression profiles of quantitative
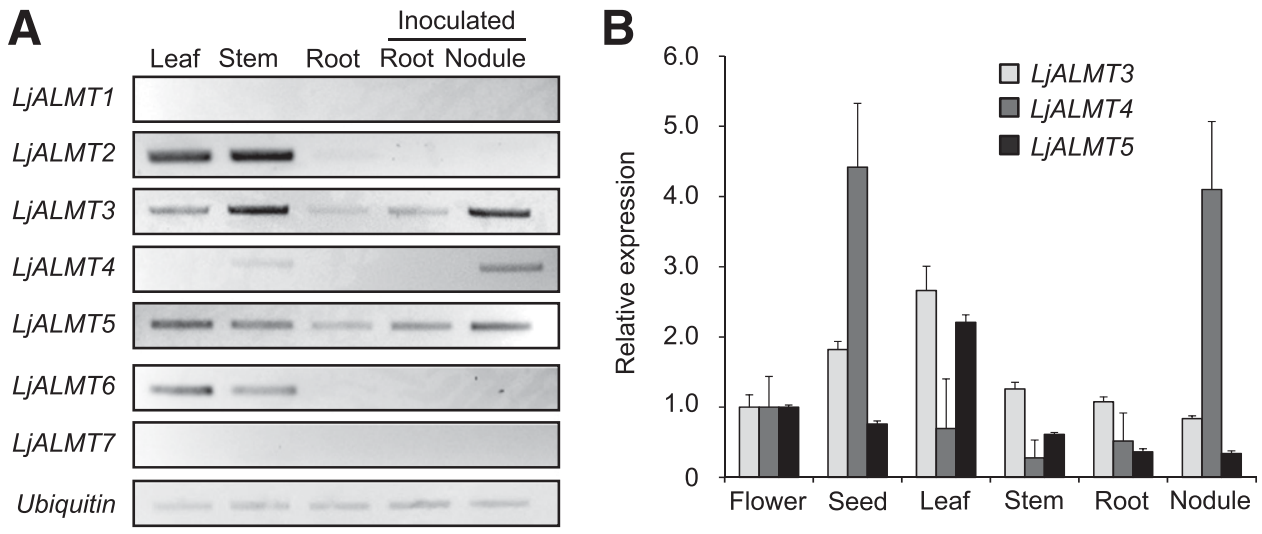

Fig. 1. Organ-specific expression of LjALMT genes. Assessment of the Lotus japonicus genome database identified seven putative full-length aluminumactivated malate transporter (ALMT) genes. A, Semiquantitative reverse transciption-polymerase chain reaction (RT-PCR) analysis showed that three of the seven $A L M T$ genes were expressed in the nodules. B, The expression profiles of three $A L M T$ genes were analyzed by quantitative RT-PCR analysis.

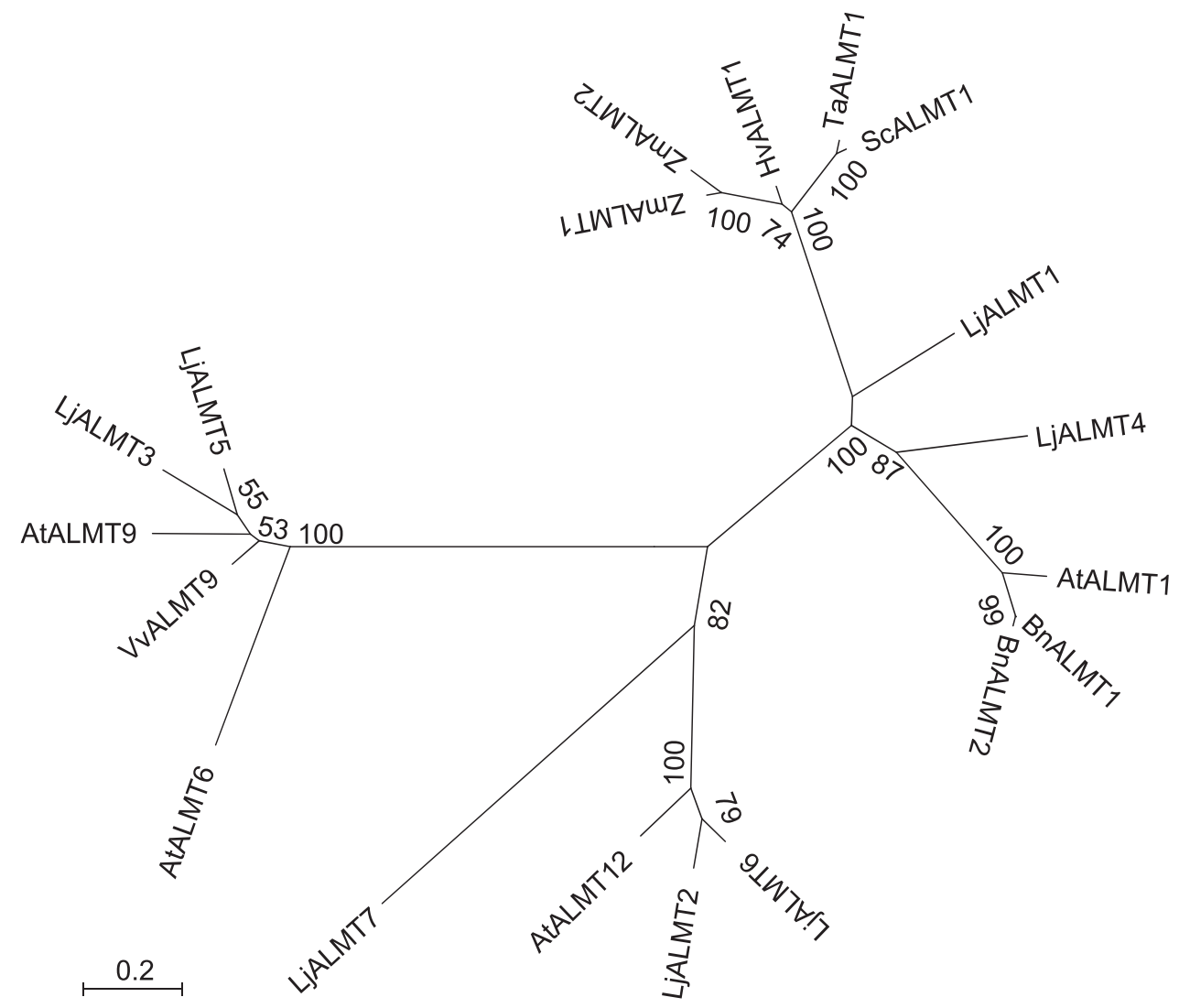

Fig. 2. Unrooted phylogenetic analysis of plant ALMTs. A phylogenetic tree was generated using MEGA 6.0 software (Tamura et al. 2013). Sequences of reported ALMT proteins were aligned using the ClustalW program, and a phylogenetic tree was constructed by the maximum likelihood method with 1,000 bootstrap replicates. Accession numbers and plant species are listed in Supplementary Table S2. 
RT-PCR were slightly different from those of semiquantitative RT-PCR, the data of quantitative RT-PCR may reflect the actual expressions more accurately than the semiquantitative RT-PCR data. It is, anyway, to be noted that the expressions of these three $A L M T$ genes were detected in nodules in both analyses.

Phylogenetic analysis indicated that LjALMT4 was grouped in the same clade as AtALMT1 and BnALMT1-2, with 45.7 to $47.2 \%$ amino acid identity (Fig. 2). The latter three proteins have been reported to mediate the efflux of malate into rhizosphere in response to aluminum exposure (Kobayashi et al. 2007; Ligaba et al. 2006). By contrast, LjALMT3 and LjALMT5 showed high sequence similarity with three tonoplast-localizing ALMTs, AtALMT6, AtALMT9, and VvALMT9, with amino acid identities ranging from 47.5 to $67.5 \%$ (Fig. 2). AtALMT6

A

$\frac{\text { LjALMT4 }}{\text { No injection Malate }} \quad \frac{\text { Water }}{\text { No injection Malate }}$

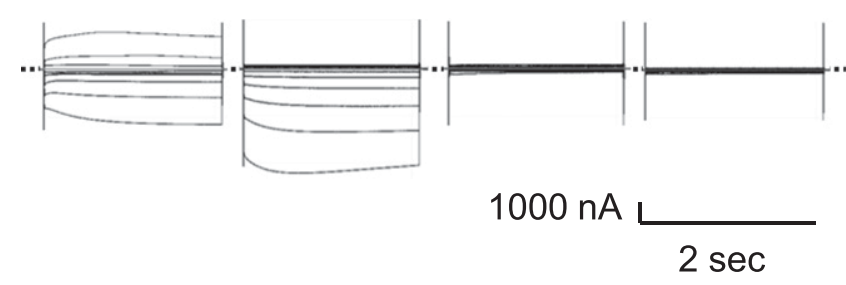

B
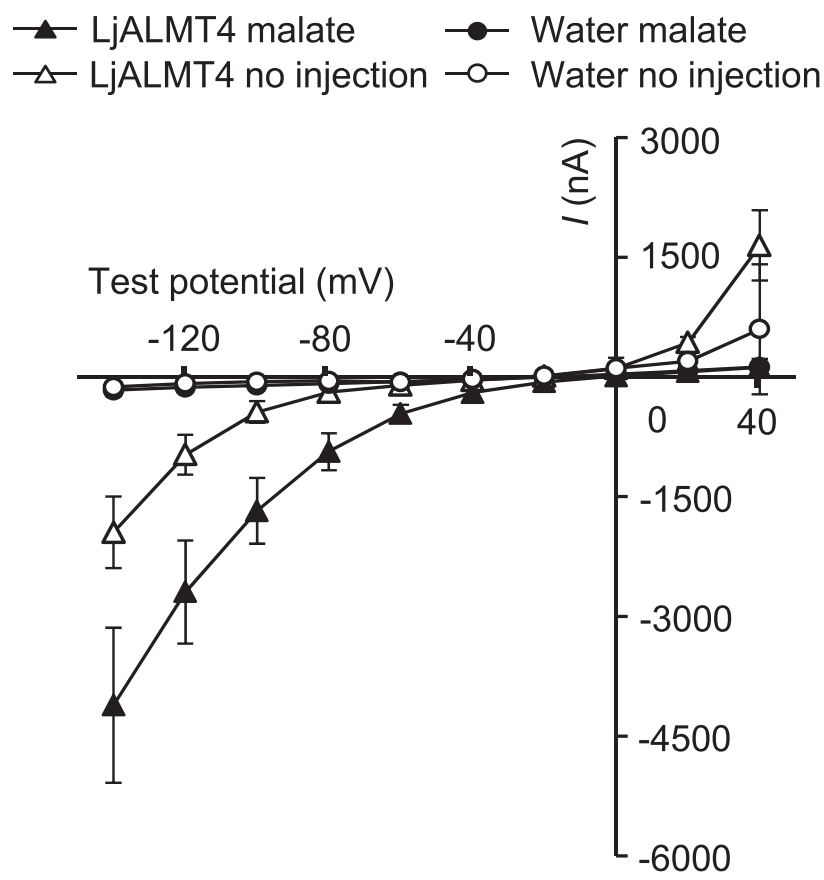

Fig. 3. Malate transport activity of LjALMT4 expressed in Xenopus laevis oocytes. A, Representative currents recorded from oocytes expressing LjALMT4 and water-injected controls. The dotted line represents zero current $(0 \mathrm{nA})$. B, Mean current-voltage curves from oocytes expressing LjALMT4 are shown. The oocytes expressing LjALMT4 and waterinjected control oocytes were used directly (no injection) or were microinjected with $50 \mathrm{nl}$ of $0.1 \mathrm{M}$ sodium malate (malate) prior to two-electrode voltage-clamp measurements. LjALMT4 clearly showed malate-dependent currents. Data are presented as the mean $\pm \mathrm{SE}$ (for LjALMT4, $n=6$, and for water control, $n=4)$. and VvALMT9 have malate transport activity, whereas AtALMT9 was found to be a chloride channel activated by malate (De Angeli et al. 2013a and b; Meyer et al. 2011). These results suggested that these three Lotus ALMTs may possess malate-transporting activity.

\section{Electrophysiological properties of LjALMTs.}

To investigate whether these three ALMTs have malate transport activity, electrophysiological experiments were performed with Xenopus oocytes, using a two-electrode voltage-clamp (TEVC) system. Each of the three LjALMT genes was fused with the green fluorescent protein $(G F P)$ gene and its complementary (c)RNA was injected into oocytes. GFP fluorescence was detected in oocytes expressing LjALMT3, LjALMT4, and LjALMT5, and cross-sections showed GFP fluorescence at the plasma membrane (Supplementary Fig. S1A).

Measurements of the voltage-dependent current of these LjALMT-expressing oocytes revealed that oocytes expressing LjALMT4 showed larger inward $(-973 \pm 248$ nA vs. $-82 \pm 22$ $\mathrm{nA}$ at $-120 \mathrm{mV})$ and outward $(1,649 \pm 438 \mathrm{nA}$ vs. $599 \pm 814 \mathrm{nA}$ at $40 \mathrm{mV}$ ) currents in the bath medium than did control oocytes (Fig. 3A and B). Injection of malate into these oocytes increased the inward current of cells expressing LjALMT4 than was observed in the absence of exogenous malate $(-2,692 \pm$ $645 \mathrm{nA}$ vs. $-973 \pm 248 \mathrm{nA}$ at $-120 \mathrm{mV}$ ), accompanied by a positive shift in reversal potential, from -24 to $-3 \mathrm{mV}$ (Fig. 3A and $\mathrm{B})$. This property was also observed in oocytes expressing LjALMT4::GFP. By contrast, injection of malate into oocytes expressing LjALMT3 or LjALMT5 did not alter cell currents (Supplementary Fig. S2). These results indicate that LjALMT4 can mediate the efflux of malate.

Free-living bacteroids can utilize various dicarboxylates as carbon source, and malate and succinate are highly permeable across peribacteroid membranes, as mentioned above. Thus, the specificity of LjALMT4 to transport substrates is of high physiological importance. To investigate the substrate specificity of LjALMT4, other organic acids were preinjected into Xenopus oocytes with LjALMT4 and TEVC experiments were performed (Fig. 4A and B). Preinjection of fumarate or succinate into cells expressing LjALMT4 resulted in higher inward currents $(-2,420 \pm 397 \mathrm{nA}$ and $-2,601 \pm 600 \mathrm{nA}$, respectively, at $-120 \mathrm{mV}$ ) than in control cells and shifted their reversal potential from -24 to $-10 \mathrm{mV}$ and from -24 to $-4 \mathrm{mV}$, respectively (Fig. 4B and C). These properties were almost identical to those observed in cells preinjected with malate (Figs. 3 and 4). In contrast, both inward and outward currents became smaller when citrate was preinjected into cells with LjALMT4 (Fig. 4A and $\mathrm{B})$. Further, the shift in reversal potential of cells preinjected with citrate was similar to that of water-injected control cells, indicating that LjALMT4 functions as a dicarboxylatespecific efflux transporter.

The selectivity of LjALMT4-expressing oocytes for inorganic anions was also investigated. When sodium chloride was present in the bath solution, LjALMT4-expressing cells mediated larger outward currents than the control, with the current depending on sodium chloride concentration (Fig. 5A and B). To assess the effect of sodium ion, tetraethylammonium chloride (TEA-Cl) was added to the bath solution in place of sodium chloride. The outward currents of LjALMT4-expressing oocytes were almost the same in $96 \mathrm{mM}$ TEA-Cl as in $96 \mathrm{mM} \mathrm{NaCl}$, indicating that LjALMT4 is an anion transporter permeable to chloride, in a similar manner to that of the Arabidopsis ALMT member AtALMT12 (Sasaki et al. 2010) (Fig. 5A and B). The anion specificity of LjALMT4 was tested by adding other anions, including nitrate, sulfate, and malate, to the bath solution. LjALMT4-expressing oocytes were most permeable to nitrate but were impermeable to malate and sulfate from outside the cells (Fig. 5A and C). 
Because SNF is a costly event, it is suppressed under an excess amount of nitrate (Streeter 1985a and b). To clarify the effect of nitrate on malate efflux activity of LjALMT4, LjALMT4expressing oocytes were preinjected with malate and the currents were measured in the bath solution containing sodium nitrate. Both inward and outward currents showed the same property with the oocytes in the chloride solution, and no alteration was observed in the malate efflux activity of LjALMT4 (Supplementary Fig. S3).

The malate transport activity of some ALMTs was reported to be directly activated by interacting with aluminum ions. To determine whether LjALMT4 is directly activated by aluminum, this ion was added to the bath solutions. The inward currents of cells expressing LjALMT4 and preinjected with malate were not significantly affected by treatment with $100 \mu \mathrm{M} \mathrm{AlCl}_{3}$ at $\mathrm{pH} 4.5(-4.2 \% \pm 21.6$ at $-120 \mathrm{mV})$.

\section{Expression analysis of $\mathrm{LjALMT}$ genes.}

To assess organ-specific expression of LjALMT4 during $\mathrm{SNF}$, the putative promoter region of this gene ( $p L j A L M T 4)$ was fused to the $\beta$-glucuronidase (GUS) reporter gene and the construct was introduced into L. japonicus by Agrobacteriummediated transformation. Strong GUS activity was observed in transgenic root nodules but only in the root-nodule junction of young nodules and in vascular bundles of mature nodules at 28 days after inoculation (Fig. 6A and B). GUS expression was undetectable in other root tissues, including root tips. To identify the cell types expressing LjALMT4, nodule sections were prepared after GUS staining. Microscopic observation of root-nodule junction regions showed specific GUS staining in the root vascular bundles developing toward the nodules (Fig. 6C). In nodules, specific GUS staining was restricted to the vasculature, in particular around the nodule xylem (Fig. 6D). UV irradiation showed that the LjALMT4-expressing cells were cells of the vascular parenchyma, as shown by the bluish autofluorescence of the nodule xylem and vascular endodermis (Fig. 6E and F).

We also examined whether aluminum ions induced LjALMT4 expression. Using the GUS reporter, pLjALMT4::GUS transformed plants were stained after treatment with aluminum for

A

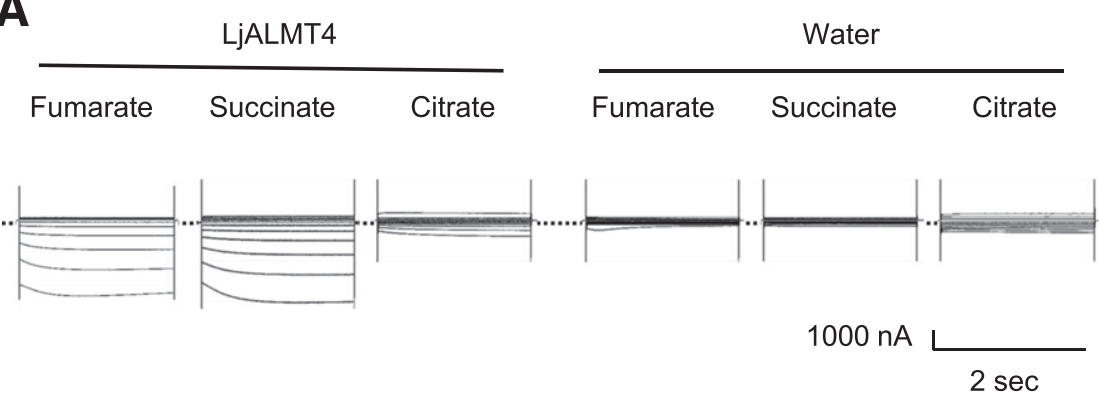

B
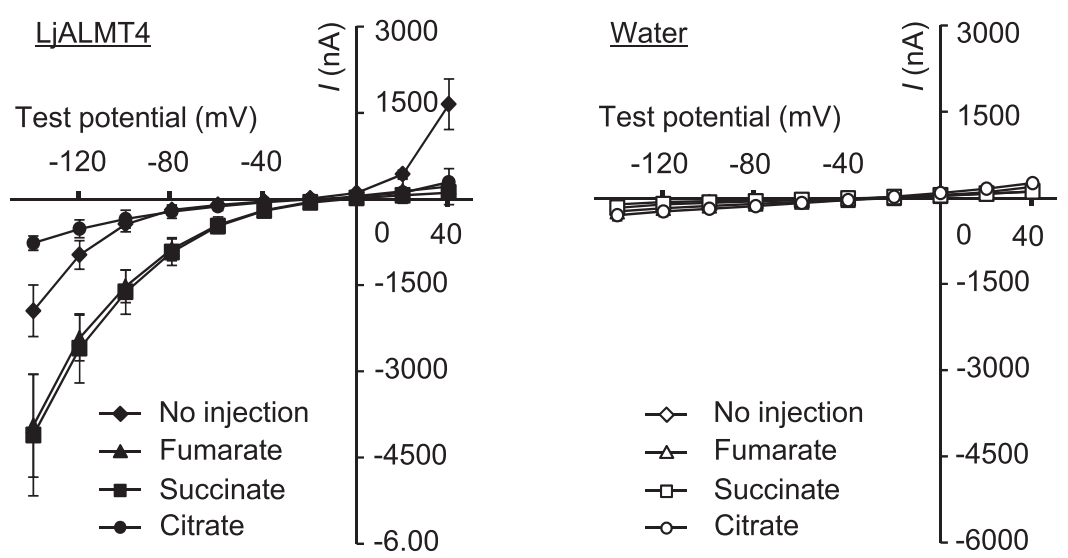

C<smiles>O=C([O-])CC(O)C(=O)[O-]</smiles>

Malate<smiles>O=C([O-])C=CC(=O)[O-]</smiles>

Fumarate<smiles>O=C([O-])CCC(=O)[O-]</smiles><smiles>O=C([O-])CC(O)(CC(=O)[O-])C(=O)[O-]</smiles>

Succinate

Citrate

Fig. 4. Dicarboxylate-specific currents mediated by LjALMT4. A, Representative currents recorded from oocytes expressing LjALMT4 with or without preloading of fumarate, succinate, or citrate. Water-injected oocytes were used as controls. B, Mean current-voltage curves from oocytes expressing LjALMT4 (left) and water-injected controls (right). Oocytes were injected with several sodium salts of organic acids. LjALMT4 showed specific transport activity for dicarboxylates. C, Structures of carboxylates used in the transport assay. 
3 h. However, no alteration of GUS expression was observed, indicating that LjALMT4 is not associated with aluminum detoxification, unlike AtALMT1 and TaALMT1, despite having a transport substrate in common.

GUS analysis using the putative promoter region of $L j A L M T 3$ or LjALMT5 was also examined. The GUS staining of LjALMT5 in the nodules was exactly the same as that of LjALMT4 (Supplementary Fig. S4), whereas GUS expression in the nodules was undetectable with the LjALMT3 putative promoter region. The lack of GUS staining of LjALMT3 in this assay suggested that the used putative promoter region of LjALMT3 may not be long enough to show the nodule expression of the gene.

To investigate the subcellular localization of LjALMTs, each open reading frame was fused with GFP, and the resulting LjALMTs::GFP was introduced into onion epidermal cells by particle bombardment. GFP fluorescence of LjALMT4::GFP

A $\quad \mathrm{NaCl} 96 \mathrm{mM} \quad \mathrm{NaCl} 48 \mathrm{mM} \quad$ TEA-Cl $96 \mathrm{mM} \quad \mathrm{NaNO}_{3} 48 \mathrm{mM}$

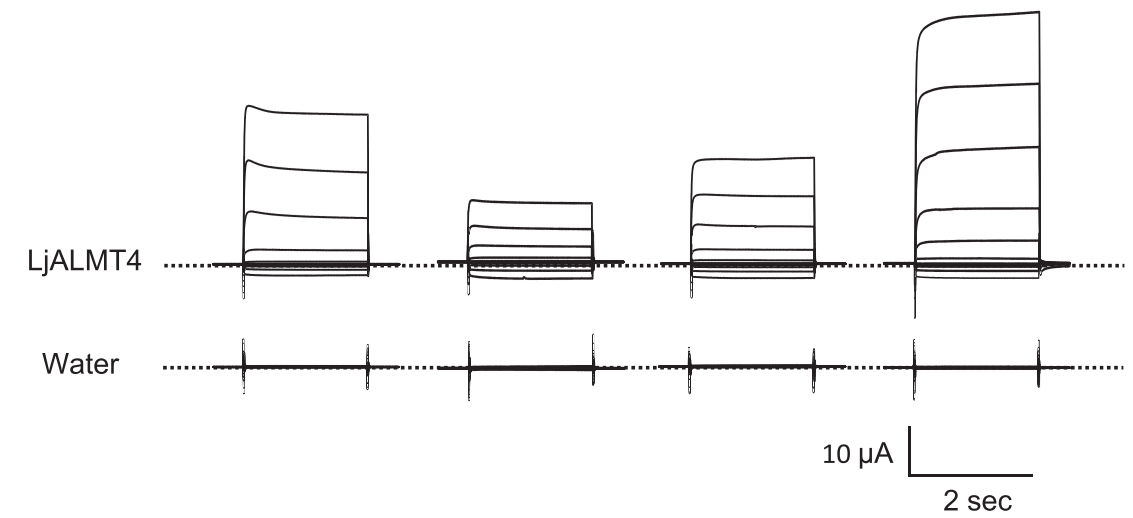

B
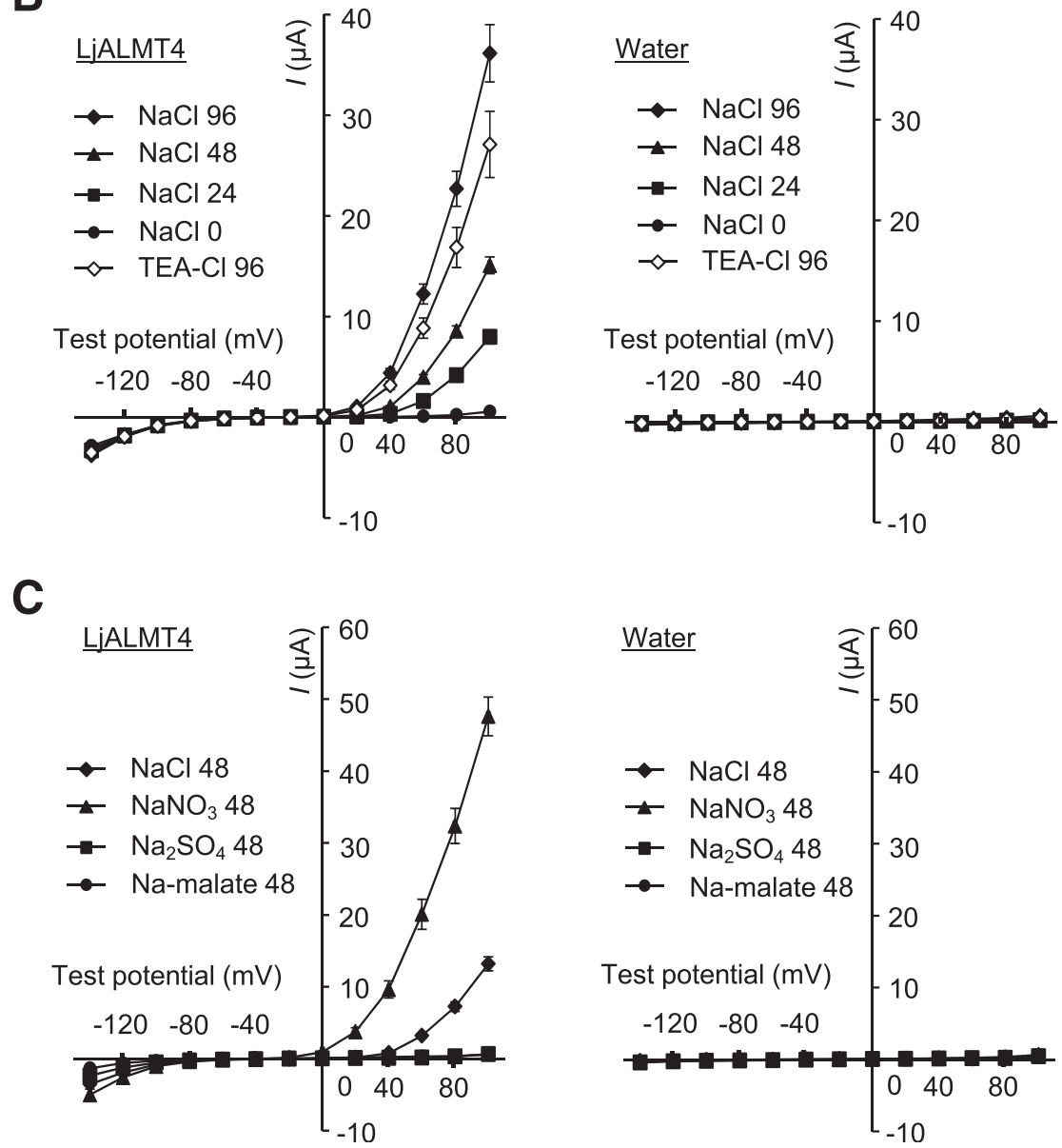

Fig. 5. Electrophysiological properties of LjALMT4. A, Representative currents recorded from oocytes expressing LjALMT4 in the presence or absence of various anions in the bath solutions. Water-injected oocytes were used as controls. B, Effect of chloride concentrations on LjALMT4-mediated currents. The bath solutions include various concentrations $(0$ to $96 \mathrm{mM})$ of $\mathrm{NaCl}$ or $96 \mathrm{mM}$ tetraethylammonium chloride (TEA-Cl), which were adjusted to the same osmolality with sorbitol $\left(210 \mathrm{mOsm} \mathrm{kg}{ }^{-1}\right)$. C, Effect of anions in bath solutions on LjALMT4-mediated currents. The bath solutions include $48 \mathrm{mM} \mathrm{NaCl}$, $\mathrm{NaNO}_{3}, \mathrm{Na}_{2} \mathrm{SO}_{4}$, or sodium malate. LjALMT4 mediated the influx of $\mathrm{NO}_{3}{ }^{-}$and $\mathrm{Cl}^{-}$. Data are presented as the mean \pm standard error (for LjALMT4, $n=6$, and for water control, $n=4)$. 
was detected both in the plasma membrane and endomembranes, while fluorescences from both LjALMT3 and LjALMT5 fusion protein were observed on the tonoplast (Fig. 7). It is as expected that both LjALMT3 and LjALMT5 are localized on tonoplast, because all characterized ALMT members in this clade revealed vacuolar localization, while LjALMT4, classified in the different clade, does not localize vacuolar membrane.

\section{DISCUSSION}

Transport of organic acids and regulation of transport events during SNF are important in the exchange of photosynthates and fixed nitrogen compounds between plant cells and bacteroids. Analysis in a nonlegume plant, Alnus glutinosa, identified a member of the nitrate transporter family as being involved in malate transport through the peribacteroid membrane (Jeong et al. 2004). In contrast, no dicarboxylate transporters have been reported in legume plants since the peribacteroid membrane was shown to be permeable to dicarboxylates (Udvardi et al. 1988). This study focused on ALMT proteins in L. japonicus as candidate dicarboxylate transporters and characterized the possible role of LjALMT4 in the nodules.

Although seven full-length $A L M T$ genes were found in the Lotus genome, other model legumes were found to have many more of these genes. For example, the genomes of Glycine max and Medicago truncatula were found to have 31 and 18 fulllength ALMT genes, respectively (Schmutz et al. 2010; Young et al. 2011). GmALMT1 was characterized as a malate transporter involved in responses to environmental stresses such as phosphorus deficiency and aluminum exposure (Liang et al. 2013; Wu et al. 2013). Phylogenetic analysis of some transporter families, e.g., ABC proteins, showed the formation of legume-specific clades, with some proteins in the clade induced during SNF (Banasiak and Jasinski 2014; Takanashi and Yazaki 2014). Construction of a phylogenetic tree based on the ALMTs of Glycine max and Medicago truncatula showed that the ALMT family also forms a legume-specific clade, to which LjALMT7 belongs (Supplementary Fig. S5), whereas the expression of LjALMT7 was not detectable in the nodules. These data suggest that, during molecular evolution, ALMTs functioning in the nodules were recently recruited from members of the ALMT family with other physiological roles in plants.

Substrate specificity is not well understood in ALMT members. Two Arabidopsis ALMTs, AtALMT6 and AtALMT9, were found to have almost the same transport activity for malate and fumarate (Kovermann et al. 2007; Meyer et al. 2011), and a barley ALMT, HvALMT1, was shown to mediate the efflux of malate and succinate and, possibly, fumarate, in a homologous system (Gruber et al. 2011). In TEVC experiments, LjALMT4 showed efflux activity for malate, fumarate, and succinate, suggesting that members of the ALMT family may be unable to distinguish among the chemical structures of these three similar dicarboxylates.

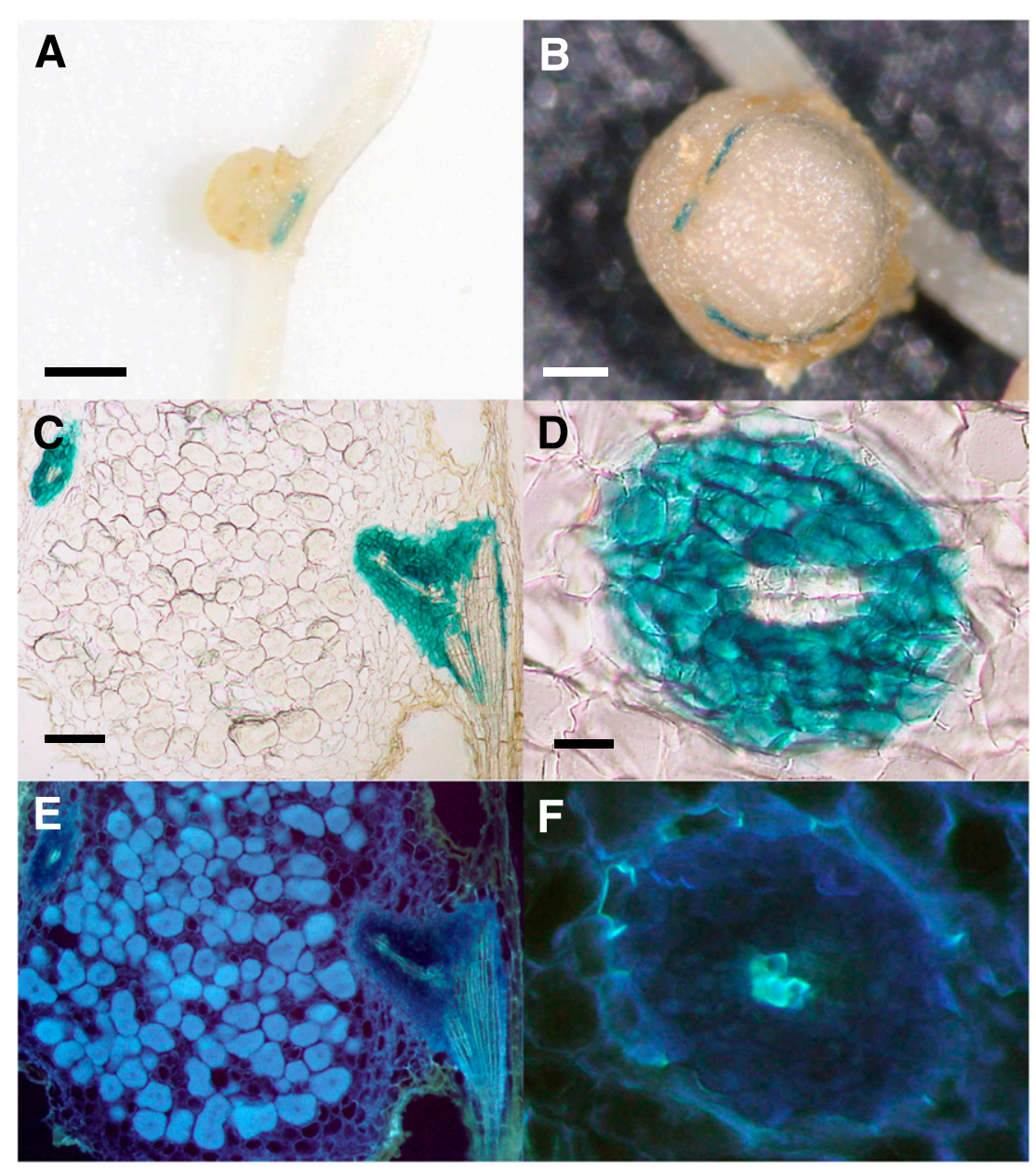

Fig. 6. $\beta$-Glucuronidase (GUS) staining of $p L j A L M T 4:: G U S$ transformants. GUS staining of LjALMT4 was detected in the A, root-nodule junctions of young nodules and $\mathbf{B}$, nodule vascular bundles of mature nodules. $\mathbf{C}$ through $\mathbf{F}$, Cross-sections of the nodules of a pLjALMT4::GUS transformant. $\mathbf{C}$, GUS staining observed in the vascular parenchyma cells in the nodule. D, Magnifications of C. E and F, Panels C and D under UV light, respectively. Bars $=200 \mu \mathrm{m}(\mathrm{A}$ and B), $100 \mu \mathrm{m}(\mathrm{C})$ and $10 \mu \mathrm{m}(\mathrm{D})$. 
Preinjection of citrate into LjALMT4-expressing cells reduced outward current, inhibiting the increased current mediated by expression of LjALMT4 in oocytes. Citrate was recently reported to act as an open channel blocker of Arabidopsis AtALMT9 (Zhang et al. 2013). Addition of citrate to the cytosol of AtALMT9-expressing tobacco vacuoles reduced the malate inward current, as shown by the patch clamp technique, with three positively charged amino acid residues, K193, R200, and R215, being necessary for citrate inhibition of AtALMT9 (Zhang et al. 2013). ClustalW alignment showed that LjALMT4 has two residues corresponding to K193 and R215 but no positively charged residue corresponding to R200 (Supplementary Fig. S6), suggesting that citrate reduces LjALMT4-associated current by other mechanisms.

LjALMT4 was found to mediate the influx of inorganic anions such as chloride and nitrate. To date, several ALMTs have been reported to transport both dicarboxylates and inorganic anions (Gruber et al. 2010; Kovermann et al. 2007; Ligaba et al. 2012; Meyer et al. 2010; Piñeros et al. 2008). Wheat TaALMT1 was most similar in transport activity to LjALMT4, although only $41 \%$ of their amino acids were identical. To determine the domains that confer substrate specificity to ALMTs, one or both domain swapping or point mutation analyses are required. For example, recent studies of TaALMT1 suggested putative domains and amino acid residues necessary for the aluminum activation of malate efflux (Furuichi et al. 2010; Ligaba et al. 2009, 2013; Sasaki et al. 2014).

Promoter GUS analysis showed that LjALMT4 is expressed only in nodule vascular parenchyma cells. Our previous tissue-specific transcriptome analysis suggested that several genes in glycolysis and the citrate cycle, including a malate

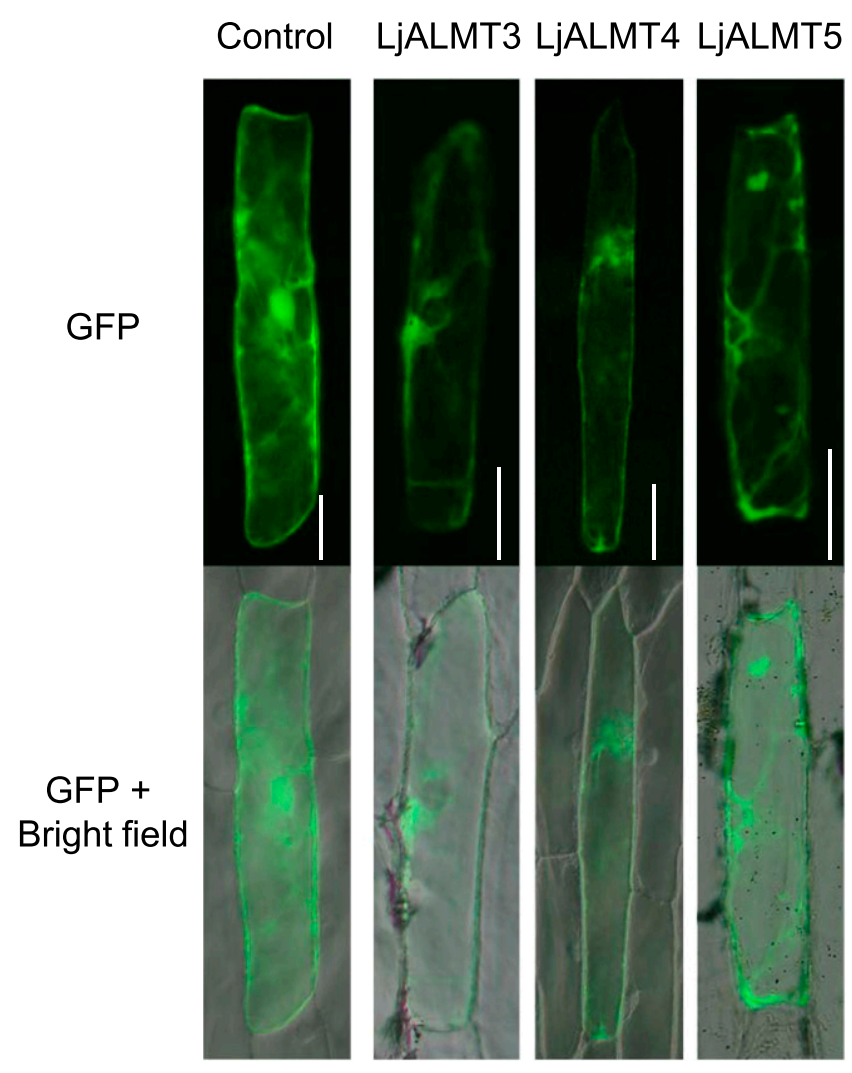

Fig. 7. Subcellular localization of LjALMT proteins. Green fluorescent protein was fused to the C-terminal end of the LjALMT protein and was transiently expressed in onion epidermal cells. LjALMT4 localized to the plasma membrane and endomembrane, while both LjALMT3 and LjALMT5 localized at the tonoplast. Bars $=100 \mu \mathrm{m}$. dehydrogenase, were expressed in the vascular bundles and cortex cells of the nodules (Takanashi et al. 2012). LjALMT4 may function by providing an apoplastic supply of dicarboxylates, which were produced in the nodule vascular parenchyma cells, and by maintaining anion homeostasis in nodule tissues.

Of the seven ALMTs found in the L. japonicus genome database (ver. 2.5), only three were expressed in nodules, with only LjALMT4 mediating the efflux of dicarboxylates in the nodule vascular bundle. Contrary to this, LjALMT5 functions in the tonoplast of nodule vascular bundle with unknown transport substrate. Another member, LjALMT3, also localized in the tonoplast, but the cells expressing this member could not be identified in nodules. Because it is reported that a protein in the symbiosome space was localized at the vacuole when expressed in nonnodulated root cells (Meckfessel et al. 2012), LjALMT3 may localize in the peribacteroid membrane. However, LjALMT3 and LjALMT5 did not mediate the efflux of dicarboxylates in our experiments. There are some possible explanations why oocytes expressing LjALMT3 or LjALMT5 did not show the efflux activities for dicarboxylates. One of those is that both ALMTs favor other compounds than dicarboxylates as transport substrates, and another is a possible subtle misfolding of proteins at the oocyte plasma membrane, leading to loss of or strong decrease in the transport activity. To evaluate these possibilities, the transport assay of these two ALMTs should be done in other heterologous expression systems in the future.

Our findings suggested that all seven ALMTs found in the Lotus genome may not be involved in directly supplying dicarboxylates to the bacteroid at the peribacteroid membrane. Further analyses of malate transporters, not limited to ALMT, in nodules of L. japonicus will enhance understanding of the overall pathways by which dicarboxylate is supplied to the bacteroid.

\section{MATERIALS AND METHODS}

Plant materials and growth conditions.

Seeds of L. japonicus MG-20 Miyakojima were surfacesterilized with $1 \%$ sodium hypochloride for $10 \mathrm{~min}$, were rinsed five times with sterile distilled water, and were allowed to germinate on water agar plates $(0.8 \%)$. Five-day-old seedlings were transferred on sterile vermiculite with liquid $1 / 2 \mathrm{~B} \& \mathrm{D}$ medium (Broughton and Dilworth 1971) in a plant box and were grown in a cultivation chamber under a 16-h-day and 8-h-night cycle at $23^{\circ} \mathrm{C}$.

\section{RT-PCR analysis.}

For organ-specific expression analysis, total RNA was extracted from mature leaves, stems, and roots of 30-day-old plants. For inoculated roots and nodules, 7-day-old seedlings were inoculated with Mesorhizobium loti MAFF303099 and were harvested 23 days later and RNA was extracted. The resulting RNA was reverse transcribed using SuperscriptIII reverse transcription (Invitrogen), followed by semiquantitative RT-PCR $\left(95^{\circ} \mathrm{C}\right.$ for $1 \mathrm{~min} ; 34$ cycles at $95^{\circ} \mathrm{C}$ for $20 \mathrm{~s}, 52^{\circ} \mathrm{C}$ or $55^{\circ} \mathrm{C}$ for $30 \mathrm{~s}$, and $72^{\circ} \mathrm{C}$ for $20 \mathrm{~s}$ ) using Go Taq DNA polymarase (Promega) with the sets of primers specific to ALMT genes. Ubiquitin was used as a control. Quantitative RT-PCR was performed using Thunderbird Probe qPCR Mix (Toyobo) with the StepOnePlus realtime PCR system (Thermo Fisher). The sets of primers are listed in Supplementary Table S1. ATP synthase was used as a control (Suzaki et al. 2013), and expression level is indicated relative to that in flowers.

\section{Electrophysiology using Xenopus laevis oocytes.}

The coding sequence of LjALMTs was amplified with Phusion high-fidelity DNA polymerase (Thermo Fisher Scientific) 
using the primers Lj1-3CDS_Fw1 and Lj1-3CDS_Rv1 and was cloned into pENTR1A (Invitrogen). Subsequently, pENTR1ALjALMT was used for the LR reaction with $\mathrm{pXBG}-\mathrm{GW}$ to yield pXBG-LjALMTs and cRNA was prepared as described (Sasaki et al. 2010).

TEVC analysis was performed as described (Furuichi et al. 2010, Sasaki et al. 2014). Xenopus oocytes were injected with cRNA (40 ng per oocyte) or water (water control) and were kept for 2 to 3 days in modified Barth's solution (Furuichi et al. 2010; Goldin 1992; Sasaki et al. 2014). Each oocyte was preinjected with $50 \mathrm{nl}$ of $0.1 \mathrm{M}$ sodium malate, sodium fumarate, sodium succinate, or sodium citrate $(\mathrm{pH} 7.5) 0.5$ to $1.5 \mathrm{~h}$ before the start of the TEVC measurements. Oocyte membranes were clamped to the holding potentials $(-20 \mathrm{mV})$, and voltage pulses were applied in $20-\mathrm{mV}$ increments from -140 to $+40 \mathrm{mV}$. Steady-state currents were obtained at the end of the test pulse. The oocytes were incubated in a bath solution, consisting of a modified ND96 (96 mM NaCl, $1.8 \mathrm{mM} \mathrm{CaCl}_{2}, 1 \mathrm{mM} \mathrm{KCl}$, $0.1 \mathrm{mM} \mathrm{LaCl}$ ), with pH adjusted to 5.6 with $10 \mathrm{mM}$ MESbistris propane and osmolality adjusted to $210 \mathrm{mOsm} \mathrm{kg}^{-1}$ with sorbitol. TEVC recordings were obtained with amplifiers MEZ7200 and CEZ-1200 with the SET-1201 step pulse generator (Nihon Kohden) and a LabTrax A/D converter (World Precision Instruments) system or Axoclamp 900A (Molecular Devices) equipped with a DigiData 1440A data acquisition system (Molecular Devices). Voltage pulses were analyzed using DataTrax 2 (World Precision Instruments) or pClamp 10 (Molecular Devices) software. All recordings were obtained at $20^{\circ} \mathrm{C}$. To assess whether aluminum activated LjALMT4 activity, $\mathrm{AlCl}_{3}$ was added to the bath solution $(\mathrm{pH} 4.5)$ to a final concentration of $100 \mu \mathrm{M}$ (Sasaki et al. 2014). Each experiment was performed with at least two batches of oocytes from two different donor frogs, and representative data were shown.

\section{GUS staining.}

The putative promoter region of LjALMT3 ( -1 to $-3,998)$, LjALMT4 (-1 to $-1,987)$, or LjALMT5 (-1 to $-2,000)$ was amplified from the genomic DNA of MG-20, using Phusion high-fidelity DNA polymerase (Thermo Fisher Scientific) and the specific primer pairs Lj3-5Prom_Fw and Lj3-5Prom_Rv subcloned into pENTR1A, followed by transfer into pGWB3 (Nakagawa et al. 2007). The constructs were introduced into L. japonicus by Agrobacterium rhizogenes (LBA1334)-mediated transformation (Kumagai and Kouchi 2003). This strain was imported on license from the Ministry of Agriculture, Forestry and Fisheries of Japan. Nodules were sampled 28 days later and were stained for GUS as described (Takanashi et al. 2011).

\section{Membrane localization.}

The coding sequences of $L j A L M T$ genes, without a stop codon, were cloned into pENTR1A with the primer pairs Lj35CDS_Fw1 and Lj3-5CDS_Rv2 and were then subcloned into pGWB5 (Nakagawa et al. 2007). Particle bombardment with the plasmid was performed as described (Ohara et al. 2010).

For localization analysis in oocytes, the LjALMT-GFP fragment from $\mathrm{pGWB5}$-LjALMT was amplified, using primer pairs Lj3-5CDS_Fw2 and sGFP_Rv. The PCR product was cloned into pENTR-D/TOPO (Invitrogen) and was then subcloned into pXBG-GW, using a Gateway System (Invitrogen).

\section{ACKNOWLEDGMENTS}

This research was supported by grants from the Japan Society for the Promotion of Science (Grant-in-Aid for Young Scientists number 24880020 [K. Takanashi] and number 23780066 [A. Sugiyama]), by the Ministry of Education, Culture, Sports, Science and Technology (MEXT) as part of the Joint Research Program implemented at the Institute of Plant Science and Resources of Okayama University, and by the Japan Advanced Plant
Science Research Network. We also thank Research Institute for Sustainable Humanosphere (RISH), Kyoto University for an additional research grant. We thank the National Bioresource Project (Lotus japonicus, Glycine max) for providing L. japonicus seeds, T. Nakagawa (Shimane University, Japan) for providing pGWB vectors, and M. den Dulk-Ras (Leiden University, The Netherlands) for providing Agrobacterium rhizogenes LBA1334. We also thank I. C. Mori (Okayama University, Japan) for technical advice.

\section{LITERATURE CITED}

Banasiak, J., and Jasinski, M. 2014. Defence, symbiosis and ABCG transporters. Pages 163-184 in: Plant ABC transporters. M. Geisler, ed. Springer, Cham, Switzerland.

Broughton, W. J., and Dilworth, M. J. 1971. Control of leghaemoglobin synthesis in snake beans. Biochem. J. 125:1075-1080

Clarke, V. C., Loughlin, P. C., Gavrin, A., Chen, C., Brear, E. M., Day, D. A., and Smith, P. M. 2015. Proteomic analysis of the soybean symbiosome identifies new symbiotic proteins. Mol. Cell. Proteomics 14:1301-1322.

De Angeli, A., Baetz, U., Francisco, R., Zhang, J., Chaves, M. M., and Regalado, A. 2013a. The vacuolar channel VvALMT9 mediates malate and tartrate accumulation in berries of Vitis vinifera. Planta 238:283-291.

De Angeli, A., Zhang, J., Meyer, S., and Martinoia, E. 2013b. AtALMT9 is a malate-activated vacuolar chloride channel required for stomatal opening in Arabidopsis. Nat. Commun. 4:1804

Delhaize, E., Ryan, P. R., Hebb, D. M., Yamamoto, Y., Sasaki, T., and Matsumoto, H. 2004. Engineering high-level aluminum tolerance in barley with the ALMT1 gene. Proc. Natl. Acad. Sci. U.S.A. 101:15249-15254.

Furuichi, T., Sasaki, T., Tsuchiya, Y., Ryan, P. R., Delhaize, E., and Yamamoto, Y. 2010. An extracellular hydrophilic carboxy-terminal domain regulates the activity of TaALMT1, the aluminum-activated malate transport protein of wheat. Plant J. 64:47-55.

Goldin, A. L. 1992. Maintenance of Xenopus laevis and oocyte injection. Methods Enzymol. 207:266-279.

Gruber, B. D., Delhaize, E., Richardson, A. E., Roessner, U., James, R. A. Howitt, S. M., and Ryan, P. R. 2011. Characterisation of HvALMT1 function in transgenic barley plants. Funct. Plant Biol. 38:163-175.

Gruber, B. D., Ryan, P. R., Richardson, A. E., Tyerman, S. D., Ramesh, S., Hebb, D. M., Howitt, S. M., and Delhaize, E. 2010. HvALMT1 from barley is involved in the transport of organic anions. J. Exp. Bot. 61:1455-1467.

Herridge, D. F., Peoples, M. B., and Boddey, R. M. 2008. Global inputs of biological nitrogen fixation in agricultural systems. Plant Soil 311:1-18.

Hoekenga, O. A., Maron, L. G., Piñeros, M. A., Cançado, G. M., Shaff, J., Kobayashi, Y., Ryan, P. R., Dong, B., Delhaize, E., Sasaki, T., Matsumoto, H., Yamamoto, Y., Koyama, H., and Kochian, L. V. 2006. AtALMT1, which encodes a malate transporter, is identified as one of several genes critical for aluminum tolerance in Arabidopsis. Proc. Natl. Acad. Sci. U.S.A. 103:9738-9743.

Jeong, J., Suh, S., Guan, C., Tsay, Y.-F., Moran, N., Oh, C. J., An, C. S. Demchenko, K. N., Pawlowski, K., and Lee, Y. 2004. A nodule-specific dicarboxylate transporter from alder is a member of the peptide transporter family. Plant Physiol. 134:969-978.

Kobayashi, Y., Hoekenga, O. A., Itoh, H., Nakashima, M., Saito, S., Shaff, J. E., Maron, L. G., Piñeros, M. A., Kochian, L. V., and Koyama, H. 2007. Characterization of AtALMT1 expression in aluminum-inducible malate release and its role for rhizotoxic stress tolerance in Arabidopsis. Plant Physiol. 145:843-852.

Kovermann, P., Meyer, S., Hörtensteiner, S., Picco, C., Scholz-Starke, J., Ravera, S., Lee, Y., and Martinoia, E. 2007. The Arabidopsis vacuolar malate channel is a member of the ALMT family. Plant J. 52:1169-1180.

Kumagai, H., and Kouchi, H. 2003. Gene silencing by expression of hairpin RNA in Lotus japonicus roots and root nodules. Mol. Plant-Microbe Interact 16:663-668.

Léran, S., Varala, K., Boyer, J. C., Chiurazzi, M., Crawford, N., DanielVedele, F., David, L., Dickstein, R., Fernandez, E., Forde, B., Gassmann, W., Geiger, D., Gojon, A., Gong, J. M., Halkier, B. A., Harris, J. M., Hedrich, R., Limami, A. M., Rentsch, D., Seo, M., Tsay, Y. F., Zhang, M., Coruzzi, G., and Lacombe, B. 2014. A unified nomenclature of NITRATE TRANSPORTER 1/PEPTIDE TRANSPORTER family members in plants. Trends Plant Sci. 19:5-9.

Liang, C., Piñeros, M. A., Tian, J., Yao, Z., Sun, L., Liu, J., Shaff, J., Coluccio, A., Kochian, L. V., and Liao, H. 2013. Low pH, aluminum, and phosphorus coordinately regulate malate exudation through GmALMT1 to improve soybean adaptation to acid soils. Plant Physiol. 161:1347-1361.

Ligaba, A., Dreyer, I., Margaryan, A., Schneider, D. J., Kochian, L., and Piñeros, M. 2013. Functional, structural and phylogenetic analysis of domains underlying the Al sensitivity of the aluminum-activated malate/anion transporter, TaALMT1. Plant J. 76:766-780. 
Ligaba, A., Katsuhara, M., Ryan, P. R., Shibasaka, M., and Matsumoto, H. 2006. The BnALMT1 and BnALMT2 genes from rape encode aluminumactivated malate transporters that enhance the aluminum resistance of plant cells. Plant Physiol. 142:1294-1303.

Ligaba, A., Kochian, L., and Piñeros, M. 2009. Phosphorylation at S384 regulates the activity of the TaALMT1 malate transporter that underlies aluminum resistance in wheat. Plant J. 60:411-423.

Ligaba, A., Maron, L., Shaff, J., Kochian, L., and Piñeros, M. 2012. Maize ZmALMT2 is a root anion transporter that mediates constitutive root malate efflux. Plant Cell Environ. 35:1185-1200.

Meckfessel, M. H., Blancaflor, E. B., Plunkett, M., Dong, Q., and Dickstein, R. 2012. Multiple domains in MtENOD8 protein including the signal peptide target it to the symbiosome. Plant Physiol. 159:299-310.

Meyer, S., Mumm, P., Imes, D., Endler, A., Weder, B., Al-Rasheid, K. A., Geiger, D., Marten, I., Martinoia, E., and Hedrich, R. 2010. AtALMT12 represents an R-type anion channel required for stomatal movement in Arabidopsis guard cells. Plant J. 63:1054-1062.

Meyer, S., Scholz-Starke, J., De Angeli, A., Kovermann, P., Burla, B., Gambale, F., and Martinoia, E. 2011. Malate transport by the vacuolar AtALMT6 channel in guard cells is subject to multiple regulation. Plant J. 67:247-257.

Nakagawa, T., Kurose, T., Hino, T., Tanaka, K., Kawamukai, M., Niwa, Y., Toyooka, K., Matsuoka, K., Jinbo, T., and Kimura, T. 2007. Development of series of gateway binary vectors, pGWBs, for realizing efficient construction of fusion genes for plant transformation. J. Biosci. Bioeng. 104:34-41.

Ohara, K., Sasaki, K., and Yazaki, K. 2010. Two solanesyl diphosphate synthases with different subcellular localizations and their respective physiological roles in Oryza sativa. J. Exp. Bot. 61:2683-2692.

Oldroyd, G. E., Murray, J. D., Poole, P. S., and Downie, J. A. 2011. The rules of engagement in the legume-rhizobial symbiosis. Annu. Rev. Genet. 45:119-144.

Piñeros, M. A., Cançado, G. M., and Kochian, L. V. 2008. Novel properties of the wheat aluminum tolerance organic acid transporter (TaALMT1) revealed by electrophysiological characterization in Xenopus Oocytes: functional and structural implications. Plant Physiol. 147:2131-2146.

Price, G. D., Day, D. A., and Gresshoff, P. M. 1987. Rapid isolation of intact peribacteroid envelopes from soybean nodules and demonstration of selective permeability to metabolites. J. Plant Physiol. 130:157-164.

Saalbach, G., Erik, P., and Wienkoop, S. 2002. Characterisation by proteomics of peribacteroid space and peribacteroid membrane preparations from pea (Pisum sativum) symbiosomes. Proteomics 2:325-337.

Sasaki, T., Mori, I. C., Furuichi, T., Munemasa, S., Toyooka, K., Matsuoka, K., Murata, Y., and Yamamoto, Y. 2010. Closing plant stomata requires a homolog of an aluminum-activated malate transporter. Plant Cell Physiol. 51:354-365.

Sasaki, T., Tsuchiya, Y., Ariyoshi, M., Ryan, P. R., Furuichi, T., and Yamamoto, Y. 2014. A domain-based approach for analyzing the function of aluminum-activated malate transporters from wheat (Triticum aestivum) and Arabidopsis thaliana in Xenopus oocytes. Plant Cell Physiol. 55:2126-2138.

Sasaki, T., Yamamoto, Y., Ezaki, B., Katsuhara, M., Ahn, S. J., Ryan, P. R., Delhaize, E., and Matsumoto, H. 2004. A wheat gene encoding an aluminum-activated malate transporter. Plant J. 37:645-653.

Schmutz, J., Cannon, S. B., Schlueter, J., Ma, J., Mitros, T., Nelson, W., Hyten, D. L., Song, Q., Thelen, J. J., Cheng, J., Xu, D., Hellsten, U., May, G. D., Yu, Y., Sakurai, T., Umezawa, T., Bhattacharyya, M. K., Sandhu, D., Valliyodan, B., Lindquist, E., Peto, M., Grant, D., Shu, S., Goodstein, D., Barry, K., Futrell-Griggs, M., Abernathy, B., Du, J., Tian, Z., Zhu, L., Gill, N., Joshi, T., Libault, M., Sethuraman, A., Zhang, X. C., Shinozaki, K., Nguyen, H. T., Wing, R. A., Cregan, P., Specht, J., Grimwood, J., Rokhsar, D., Stacey, G., Shoemaker, R. C., and Jackson, S. A. 2010. Genome sequence of the palaeopolyploid soybean. Nature 463:178-183.

Streeter, J. G. 1985a. Nitrate inhibition of legume nodule growth and activity: II. Short term studies with high nitrate supply. Plant Physiol. 77:325-328.

Streeter, J. G. 1985b. Nitrate inhibition of legume nodule growth and activity: I. Long term studies with a continuous supply of nitrate. Plant Physiol. 77:321-324.
Suzaki, T., Kim, C. S., Takeda, N., Szczyglowski, K., and Kawaguchi, M. 2013. TRICOT encodes an AMP1-related carboxypeptidase that regulates root nodule development and shoot apical meristem maintenance in Lotus japonicus. Development 140:353-361.

Takanashi, K., Sugiyama, A., and Yazaki, K. 2011. Involvement of auxin distribution in root nodule development of Lotus japonicus. Planta 234: 73-81.

Takanashi, K., Takahashi, H., Sakurai, N., Sugiyama, A., Suzuki, H., Shibata, D., Nakazono, M., and Yazaki, K. 2012. Tissue-specific transcriptome analysis in nodules of Lotus japonicus. Mol. Plant-Microbe Interact 25: 869-876.

Takanashi, K., and Yazaki, K. 2014. ABC proteins and other transporters in Lotus japonicus and Glycine max. Pages 185-202 in: Plant ABC Transporters. M. Geisler, ed. Springer, Cham.

Tamura, K., Stecher, G., Peterson, D., Filipski, A., and Kumar, S. 2013. MEGA6: Molecular Evolutionary Genetics Analysis version 6.0. Mol. Biol. Evol. 30:2725-2729.

Udvardi, M., and Poole, P. S. 2013. Transport and metabolism in legumerhizobia symbioses. Annu. Rev. Plant Biol. 64:781-805.

Udvardi, M. K., and Day, D. A. 1997. Metabolite transport across symbiotic membranes of legume nodules. Annu. Rev. Plant Physiol. Plant Mol. Biol. 48:493-523.

Udvardi, M. K., Price, G. D., Gresshoff, P. M., and Day, D. A. 1988. A dicarboxylate transporter on the peribacteroid membrane of soybean nodules. FEBS (Fed. Eur. Biochem. Soc.) Lett. 231:36-40.

Wienkoop, S., and Saalbach, G. 2003. Proteome analysis. Novel proteins identified at the peribacteroid membrane from Lotus japonicus root nodules. Plant Physiol. 131:1080-1090.

Wu, D. M., Zhao, M., Shen, S. Y., Fu, Y. Q., Sasaki, T., Yamamoto, Y., Wei, W. H., and Shen, H. 2013. Al-induced secretion of organic acid, gene expression and root elongation in soybean roots. Acta Physiol. Plant. 35: 223-232.

Young, N. D., Debellé, F., Oldroyd, G. E., Geurts, R., Cannon, S. B., Udvardi, M. K., Benedito, V. A., Mayer, K. F., Gouzy, J., Schoof, H., Van de Peer, Y., Proost, S., Cook, D. R., Meyers, B. C., Spannagl, M., Cheung, F., De Mita, S., Krishnakumar, V., Gundlach, H., Zhou, S., Mudge, J., Bharti, A. K., Murray, J. D., Naoumkina, M. A., Rosen, B. Silverstein, K. A., Tang, H., Rombauts, S., Zhao, P. X., Zhou, P., Barbe, V., Bardou, P., Bechner, M., Bellec, A., Berger, A., Bergès, H., Bidwell, S., Bisseling, T., Choisne, N., Couloux, A., Denny, R., Deshpande, S., Dai, X., Doyle, J. J., Dudez, A. M., Farmer, A. D., Fouteau, S., Franken, C., Gibelin, C., Gish, J., Goldstein, S., González, A. J., Green, P. J., Hallab, A., Hartog, M., Hua, A., Humphray, S. J., Jeong, D. H., Jing, Y., Jöcker, A., Kenton, S. M., Kim, D. J., Klee, K., Lai, H., Lang, C., Lin, S., Macmil, S. L., Magdelenat, G., Matthews, L., McCorrison, J., Monaghan, E. L., Mun, J. H., Najar, F. Z., Nicholson, C., Noirot, C., O’Bleness, M., Paule, C. R., Poulain, J., Prion, F., Qin, B., Qu, C., Retzel, E. F., Riddle, C., Sallet, E., Samain, S., Samson, N., Sanders, I., Saurat, O., Scarpelli, C., Schiex, T., Segurens, B., Severin, A. J., Sherrier, D. J., Shi, R., Sims, S., Singer, S. R., Sinharoy, S., Sterck, L., Viollet, A., Wang, B. B., Wang, K., Wang, M., Wang, X., Warfsmann, J., Weissenbach, J., White, D. D., White, J. D., Wiley, G. B., Wincker, P., Xing, Y., Yang, L., Yao, Z., Ying, F., Zhai, J., Zhou, L., Zuber, A., Dénarié, J., Dixon, R. A., May, G. D., Schwartz, D. C., Rogers, J., Quétier, F., Town, C. D., and Roe, B. A. 2011. The Medicago genome provides insight into the evolution of rhizobial symbioses. Nature 480: 520-524.

Yurgel, S. N., and Kahn, M. L. 2004. Dicarboxylate transport by rhizobia. FEMS (Fed. Eur. Microbiol. Soc.) Microbiol. Rev. 28:489-501.

Zhang, J., Baetz, U., Krügel, U., Martinoia, E., and De Angeli, A. 2013. Identification of a probable pore-forming domain in the multimeric vacuolar anion channel AtALMT9. Plant Physiol. 163:830-843.

\section{AUTHOR-RECOMMENDED INTERNET RESOURCE}

Kazusa DNA Research Institute L. japonicus genome database: http://www.kazusa.or.jp/lotus/ 